\title{
Early-warning health and process indicators for sentinel surveillance in Madagascar 2007-2011
}

Soatiana Rajatonirina ${ }^{1}$, Fanjasoa Rakotomanana ${ }^{1}$, Laurence Randrianasolo ${ }^{1}$, Norosoa Harline Razanajatovo ${ }^{2}$, Soa Fy Andriamandimby ${ }^{2}$, Lisette Ravolomanana ${ }^{3}$, Armand Eugène Randrianarivo-Solofoniaina ${ }^{4}$, Jean-Marc Reynes ${ }^{5}$, Patrice Piola ${ }^{1}$, Alyssa Finlay-Vickers ${ }^{6}$, Jean-Michel Heraud ${ }^{2}$, Vincent Richard ${ }^{7}$

1. Unité d'Epidémiologie, Institut Pasteur de Madagascar, Antananarivo, Madagascar

2. Unité de Virologie, Institut Pasteur de Madagascar, Antananarivo, Madagascar

3. Directions des Urgences et de la Lutte contre les Maladies Négligées (DULMN), Ministère de la Santé Publique, Antananarivo, Madagascar

4. Direction de la Veille Sanitaire et de la Surveillance Epidémiologique (DVSSE), Ministère de la Santé Publique, Antananarivo, Madagascar

5. Unité de Virologie, Institut Pasteur de Madagascar. Present address: Unité de Biologie des Infections Virales Emergentes / Institut Pasteur de Lyon

6. Malaria Branch, Division of Parasitic Diseases US Centers for Disease Control and Prevention, President's Malaria Initiative, Madagascar

7. Unité d'épidémiologie, Institut Pasteur de Dakar, Dakar, Sénégal

\section{Abstract}

Background: Epidemics pose major threats in resource-poor countries, and surveillance tools for their early detection and response are often inadequate. In 2007, a sentinel surveillance system was established in Madagascar, with the aim of rapidly identifying potential epidemics of febrile or diarrhoeal syndromes and issuing alerts. We present the health and process indicators for the five years during which this system was constructed, showing the spatiotemporal trends, early-warning sign detection capability and process evaluation through timely analyses of high-quality data.

Methods: The Malagasy sentinel surveillance network is currently based on data for fever and diarrhoeal syndromes collected from 34 primary health centres and reported daily via the transmission of short messages from mobile telephones. Data are analysed daily at the Institut Pasteur de Madagascar to make it possible to issue alerts more rapidly, and integrated process indicators (timeliness, data quality) are used to monitor the system.

Results: From 2007 to 2011, 917,798 visits were reported. Febrile syndromes accounted for about $11 \%$ of visits annually, but the trends observed differed between years and sentinel sites. From 2007 to 2011, 21 epidemic alerts were confirmed. However, delays in data transmission were observed (88\% transmitted within 24 hours in 2008; 67\% in 2011) and the percentage of forms transmitted each week for validity control decreased from $99.9 \%$ in 2007 to $63.5 \%$ in 2011.

Conclusion: A sentinel surveillance scheme should take into account both epidemiological and process indicators. It must also be governed by the main purpose of the surveillance and by local factors, such as the motivation of healthcare workers and telecommunication infrastructure. Permanent evaluation indicators are required for regular improvement of the system.

Keywords: Sentinel surveillance, Madagascar, early warning, mobile phone.

Correspondence: vrichard@pasteur.sn 
DOI: 10.5210/ojphi.v6i3.5400

Copyright $\odot 2014$ the author(s)

This is an Open Access article. Authors own copyright of their articles appearing in the Online Journal of Public Health Informatics. Readers may copy articles without permission of the copyright owner(s), as long as the author and OJPHI are acknowledged in the copy and the copy is used for educational, not-for-profit purposes.

\section{Introduction}

The concept of surveillance was developed principally for control of the transmission of infections and for the early detection of outbreaks. The main elements of surveillance methods have been described elsewhere. Surveillance is a continuous, systematic process of descriptive information collection, validation, analysis, interpretation, and dissemination for use in planning, and in the implementation and evaluation of public health policies and strategies for the prevention and control of diseases or disease outbreaks [1-3]. The public health problems approached in this way, including acute and chronic diseases and environmental hazards, are diverse, necessitating the development of tools for the timely monitoring of disease trends. Furthermore, surveillance systems must be evaluated regularly, to ensure that they provide valuable information in an efficient manner $[4,5]$.

Efficient disease surveillance systems are the key to the timely detection of early-warning signs potentially signalling the occurrence of disease outbreaks or epidemics. The World Health Organisation (WHO) has highlighted the importance of improving national epidemic surveillance capacities [6,7]. Recently developed innovative tools, such as mobile telephone technology and electronic systems, have facilitated the improvement of surveillance systems, by reducing data processing [8]. However, these systems are mostly implemented in highincome countries [9], as most developing countries are faced with logistic and budgetary constraints, resulting in low-quality surveillance systems based on pen-and-paper methods. In many cases, these low-tech systems provide health institutions with inadequate support, resulting in frequent "health crises" [10]. Moreover, the healthcare infrastructure, laboratory diagnostic capacity, skills and number of physicians in these countries are generally insufficient to deal with emerging diseases likely to cause epidemics. Consequently, delays in raising the alarm often limit the possibility of an effective early response to new, emerging public health problems.

The need for an efficient sentinel surveillance network in Madagascar was highlighted by worldwide infectious disease threats to public health, such as severe acute respiratory syndrome (SARS) in 2003, avian influenza A H5N1 in 2005 and the Chikungunya epidemics observed in the Indian Ocean region in 2006. In addition, the 2005 International Health Regulations stressed the importance of commitment to the goal of global security and asked all member states to establish and implement effective surveillance and response systems, making it possible to detect and contain public health threats of national and international importance. As a result, the government of Madagascar, in partnership with the Institut Pasteur de Madagascar, established 13 fever sentinel sites in 2007, expanding the network to 34 sites by 2011, to improve the timely detection and management of febrile disease outbreaks. Two key attributes of the sentinel surveillance system are monitored continuously: timeliness and data quality. This system was designed to identify outbreaks for which public health interventions may be required early enough for such interventions to be effective. 
We report here the indicators, for 2007 to 2011, of the syndromic sentinel surveillance network, presenting spatiotemporal trends, alert detection capability and evaluations of the process on the basis of timeliness and quality data.

\section{Methods}

The sentinel surveillance network in Madagascar has been described elsewhere $[11,12]$. Briefly, it includes primary healthcare centres (sentinel sites) from across the country (Figure 1) and is managed by a national steering committee. The network was expanded from 13 influenza-like illness (ILI) sentinel sites in 2007 to 34 sentinel sites in 2011, with the aim of improving geographic coverage and representativeness of the country as a whole (4 sites are located in Antananarivo) (Figure 1). The sentinel surveillance system makes use of syndromic indicators to monitor the occurrence of selected diseases of importance for the country. The main criterion for the inclusion of cases or patients is fever or diarrhoea. For patients with fever, additional screening criteria (based on syndromic case definitions) are used to identify specific syndromes: malaria, ILI, dengue-like syndromes. Standard WHO case definitions are used, to ensure comparability $[11,12]$. Malaria diagnosis requires biologic confirmation with a positive rapid diagnostic test in patients with fever syndromes.

Cases and patients at the participating sites are identified by trained healthcare personnel participating in the surveillance network on a voluntary basis. One of the key features of the system is the timely transmission of syndromic data, on a daily basis, by coded short message service (SMS) messages sent from mobile phones. Upon reception at the IPM, the data transmitted in this manner are input daily into a specifically designed MS Access ${ }^{\circledR}$ database and analysed as soon as possible after the patients' initial visit. This results in a turnaround time of 24 hours, from data collection to reception at the IPM, even for data sent from the most remote areas of the country. The data received by SMS include: sentinel site code, date of data collection, total number of outpatient consultations, total number of confirmed malaria cases, total number of ILI cases, total number of dengue-like cases, total number of diarrhoea cases, and the number of consultations by age group. The age groups were those commonly used by the Ministry of Health in Madagascar: less than 1 year, 1-4 years, 5-14 years, 15-24 years, 25 years and over.

Surveillance data are analysed and presented in easy-to-interpret tables and graphs providing the number of cases for each syndrome monitored. In addition, daily and weekly baselines (mean number of cases in the corresponding period of previous years) are calculated for each syndrome and plotted against current observations, to identify early signs of outbreaks triggering alerts. The information is disseminated on a weekly and monthly basis to healthcare staff involved in the network and to the staff of the Ministry of Health $(\mathrm{MoH})$ in Madagascar.

\section{Ethics clearance}

The surveillance protocol was approved by the MoH and the National Ethics Committee of Madagascar. 


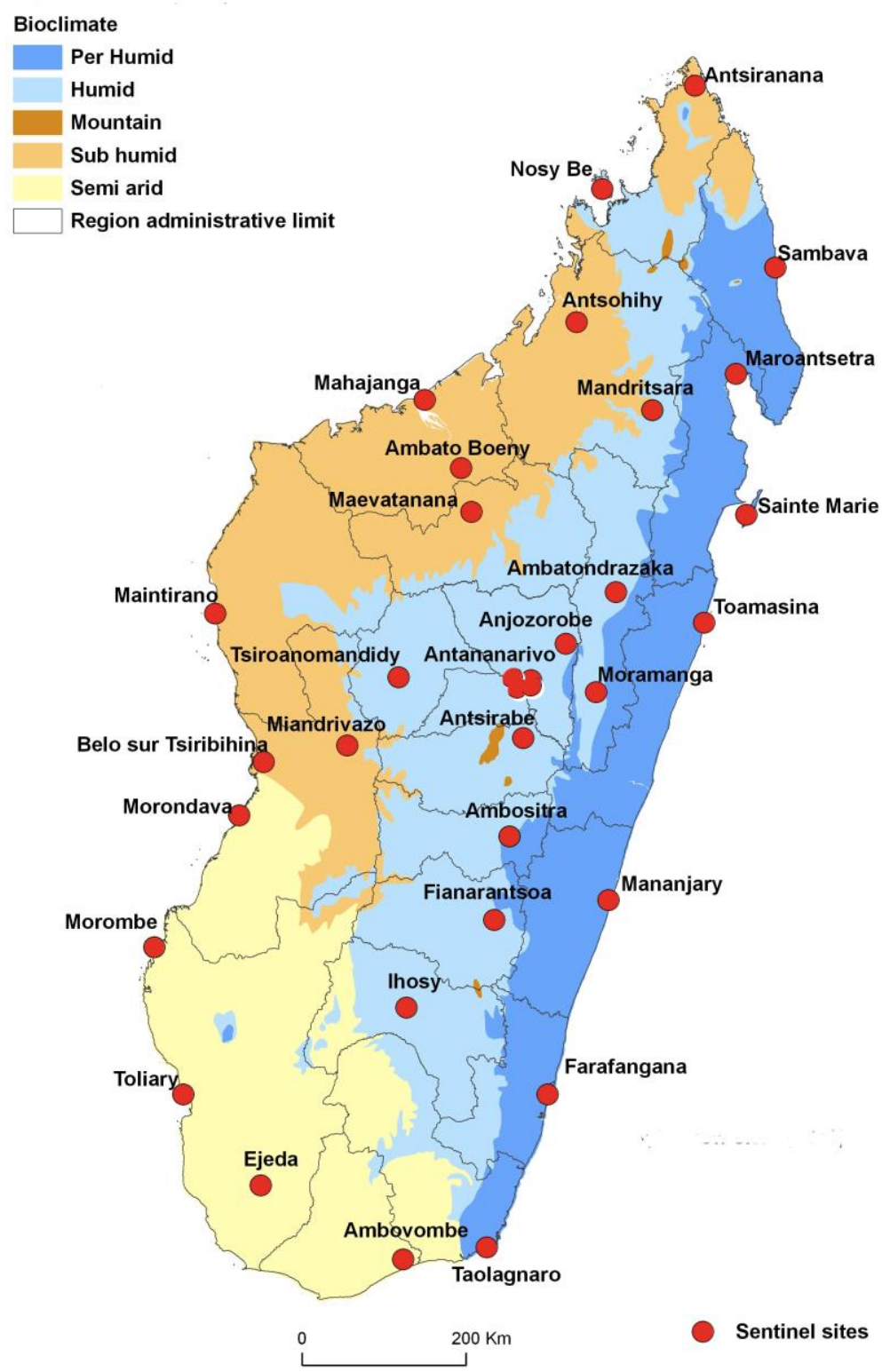

Figure1: Surrounding climate and location of the health centres participating in the sentinel surveillance system in Madagascar

\section{Results}

\section{Description of the epidemiological indicators}

From January 2007 to December 2011, the data collected on a daily basis corresponded to 917,798 visits (Table 1). The age distribution of the patients concerned, as a function of the total numbers of visits and febrile syndromes, is indicated in Table 1. In total, 102,200 cases $(11.1 \%)$ of fever were reported. Fever syndromes accounted for $12.1 \%$ of visits in 2007, $12.2 \%$ in $2008,11.8 \%$ in $2009,10.8 \%$ in 2010 and $10.0 \%$ in 2011 ( $p<0.01$, Table 2). 
Table 1: Annual distribution of visits by age group, according to SMS data

\begin{tabular}{lllllllllllll}
\hline $\begin{array}{l}\text { Age } \\
\text { group }\end{array}$ & \multicolumn{2}{c}{ All visits $(\boldsymbol{n}=917,798)$} & & & & & & & & \\
& $\mathbf{2 0 0 7}$ & & $\mathbf{2 0 0 8}$ & & $\mathbf{2 0 0 9}$ & & $\mathbf{2 0 1 0}$ & & $\mathbf{2 0 1 1}$ & \\
\hline & $n$ & $(\%)$ & $n$ & $(\%)$ & $n$ & $(\%)$ & $n$ & $(\%)$ & $n$ & $(\%)$ \\
\hline <1 year & 7,663 & $(9.6)$ & 13,794 & $(10.0)$ & 22,748 & $(10.4)$ & 24,405 & $(10.8)$ & 28,607 & $(11.2)$ \\
1 1-4 years & 12,564 & $(15.7)$ & 20,967 & $(15.2)$ & 35,652 & $(16.3)$ & 38,074 & $(16.8)$ & 44,382 & $(17.4)$ \\
5-14 years & 10,092 & $(12.6)$ & 17,836 & $(13.0)$ & 34,911 & $(15.9)$ & 32,230 & $(14.2)$ & 37,695 & $(14.8)$ \\
$15-24$ years & 16,096 & $(20.2)$ & 27,569 & $(20.1)$ & 39,421 & $(18.0)$ & 42,254 & $(18.7)$ & 49,340 & $(19.3)$ \\
$\geq 25$ years & 33,456 & $(41.9)$ & 57,356 & $(41.7)$ & 86,259 & $(39.4)$ & 89,196 & $(39.4)$ & 95,231 & $(37.3)$ \\
\hline Total & 79,871 & $(8.7)$ & 137,522 & $(15.0)$ & 218,991 & $(23.9)$ & 226,159 & $(24.6)$ & 255,255 & $(27.8)$ \\
\hline
\end{tabular}

ILI accounted for $14.7 \%$ of fever cases in $2007,8.5 \%$ in $2008,21.3 \%$ in $2009,20.2 \%$ in 2010 and $32.8 \%$ in 2011 ( $\mathrm{p}<0.01$ ), according to the data transmitted by SMS (Table 3). Dengue-like syndromes (Table 3) accounted for $18.6 \%$ of fever cases in $2007,8.7 \%$ in $2008,10.2 \%$ in $2009,11.5 \%$ in 2010 and $4.2 \%$ in 2011 ( $<<0.01$ ). Confirmed cases of malaria (Table 3) accounted for $12.0 \%$ of fever cases in $2007,8.3 \%$ in $2008,10.6 \%$ in $2009,16.8 \%$ in 2010 and $12.4 \%$ in 2011 ( $\mathrm{p}<0.01)$. From January 2008 to December $2011,40,510$ cases $(4.8 \%)$ of diarrhoea were reported in the 837,881 visits (Table 3). Diarrhoea cases accounted for $3.1 \%$ of visits in 2008, 4.9\% in 2009, 5.5\% in 2010 and 5.1\% in $2011(\mathrm{p}<0.01)$.

The epidemiological characteristics of groups with fever-related syndromes, such as those with ILI, identified by the sentinel surveillance system, were investigated by the plotting of daily count data on a graph (Figure 2). Daily and weekly counts, as a function of the regional pattern, were also plotted and analysed for each sentinel centre (data not shown). Figure 2 shows a peak in the number of daily visits in November 2009 corresponding to an increase in the number of febrile syndromes and ILI cases.

A plot of the distribution of febrile and other syndromes over the various years (Figures 2-5) showed that ILI was the dominant cause of fever in most of the country, from 2009 onwards. A subanalysis of the longitudinal data, using only the first 13 sentinel sites established in 2007-2011, yielded similar trends (Figure 4). 
Table 2: Process indicators by sentinel site and year

\begin{tabular}{|c|c|c|c|c|c|c|c|c|c|c|c|c|c|c|c|c|c|c|c|c|c|}
\hline & & 2007 & & & & 2008 & & & & 2009 & & & & 2010 & & & & 2011 & & & \\
\hline Sentinel site & $\begin{array}{l}\text { Opening } \\
\text { date }\end{array}$ & Fever & Forms & $\begin{array}{l}\text { Forms } \\
/ \text { Fever } \\
\%\end{array}$ & $\begin{array}{l}\text { SMS } \\
\text { delay } \\
\%\end{array}$ & Fever & Forms & $\begin{array}{l}\text { Forms } \\
\text { / Fever } \\
\%\end{array}$ & $\begin{array}{l}\text { SMS } \\
\text { delay } \\
\%\end{array}$ & Fever & Forms & $\begin{array}{l}\text { Forms } \\
/ \text { Fever } \\
\%\end{array}$ & $\begin{array}{l}\text { SMS } \\
\text { delay } \\
\%\end{array}$ & Fever & Forms & $\begin{array}{l}\text { Forms } \\
\text { / Fever } \\
\%\end{array}$ & $\begin{array}{l}\text { SMS } \\
\text { Delay } \\
\%\end{array}$ & Fever & Forms & $\begin{array}{l}\text { Forms } \\
\text { / Fever } \\
\%\end{array}$ & $\begin{array}{l}\text { SMS } \\
\text { Delay } \\
\%\end{array}$ \\
\hline Ambatondrazaka & $2009-05-11$ & -- & -- & -- & -- & -- & & & & 297 & 200 & 67.3 & 37 & 211 & 185 & 87.7 & 38 & 276 & 154 & 55.8 & 25 \\
\hline Ambato Boeny & 2010-09-01 & -- & -- & -- & -- & -- & & & & -- & -- & -- & -- & 363 & 53 & 14.6 & 51 & 1094 & 4 & 0.4 & 28 \\
\hline Ambovombe & 2009-06-02 & -- & -- & -- & -- & -- & & & & 111 & 111 & 100.0 & 34 & 171 & 53 & 31.0 & 53 & 190 & 73 & 38.4 & 45 \\
\hline Ambositra & 2011-08-25 & -- & -- & -- & -- & -- & & & & -- & -- & -- & -- & -- & -- & -- & -- & 212 & 195 & 92.0 & 6 \\
\hline AntananarivoBHK & $2009-01-26$ & -- & -- & -- & -- & -- & & & & 412 & 412 & 100.0 & 18 & 331 & 180 & 54.4 & 22 & 273 & 124 & 45.4 & 39 \\
\hline Antananarivo CDA & 2009-04-01 & -- & -- & -- & -- & -- & & & & 132 & 111 & 84.1 & 18 & 240 & 172 & 71.7 & 23 & 308 & 198 & 64.3 & 43 \\
\hline Antananarivo MJR & 2009-02-02 & -- & -- & -- & -- & -- & & & & 441 & 144 & 32.7 & 24 & 292 & 215 & 73.6 & 2 & 480 & 235 & 49.0 & 7 \\
\hline Antananarivo TSL & 2009-02-09 & -- & -- & -- & -- & -- & & & & 143 & 134 & 93.7 & 26 & 44 & 44 & 100.0 & 25 & 38 & 28 & 73.7 & 10 \\
\hline Antsirabe & $2008-09-08$ & -- & -- & -- & -- & 258 & 256 & 99.2 & 20 & 1304 & 1304 & 100.0 & 7 & 576 & 550 & 95.5 & 4 & 1025 & 653 & 63.7 & 4 \\
\hline Antsiranana & 2007-04-19 & 1652 & 1650 & 99.8 & NA & 2215 & 2215 & 100.0 & 10 & 2579 & 2148 & 83.3 & 5 & 1995 & 1968 & 98.6 & 10 & 1577 & 1252 & 79.4 & 11 \\
\hline Antsohihy & 2007-05-02 & 263 & 263 & 100.0 & NA & 1172 & 1172 & 100.0 & 19 & 611 & 565 & 92.5 & 29 & 585 & 558 & 95.4 & 35 & 248 & 180 & 72.6 & 23 \\
\hline Anjozorobe & $2010-07-29$ & -- & -- & -- & -- & -- & -- & -- & -- & -- & -- & & -- & 49 & 38 & 77.6 & 45 & 158 & 153 & 96.8 & 38 \\
\hline Belo sur Tsiribina & $2010-10-11$ & -- & -- & -- & -- & -- & -- & -- & -- & -- & -- & & -- & 183 & 182 & 99.5 & 48 & 529 & 419 & 79.2 & 50 \\
\hline Ejeda & $2007-12-10$ & 5 & 5 & 100.0 & NA & 63 & 63 & 100.0 & 12 & 76 & 76 & 100.0 & 10 & 113 & 113 & 100.0 & 20 & 137 & 137 & 100.0 & 24 \\
\hline Farafangana & $2007-06-07$ & 473 & 473 & 100.0 & NA & 929 & 929 & 100.0 & 6 & 970 & 961 & 99.1 & 8 & 1102 & 925 & 83.9 & 14 & 1710 & 1609 & 94.1 & 17 \\
\hline Fianarantsoa & 2008-08-04 & -- & -- & -- & -- & 250 & 250 & 100.0 & 9 & 427 & 427 & 100.0 & 10 & 162 & 145 & 89.5 & 11 & 302 & 186 & 61.6 & 11 \\
\hline Ihosy & $2007-12-10$ & 71 & 71 & 100.0 & NA & 793 & 793 & 100.0 & 9 & 552 & 525 & 95.1 & 16 & 350 & 350 & 100.0 & 19 & 745 & 538 & 72.2 & 11 \\
\hline Maevatanana & $2007-04-23$ & 1639 & 1639 & 100.0 & NA & 1906 & 1906 & 100.0 & 9 & 2736 & 2223 & 81.3 & 5 & 3414 & 3311 & 97.0 & 20 & 2582 & 1668 & 64.6 & 29 \\
\hline Mahajanga & $2007-04-23$ & 519 & 518 & 99.8 & NA & 597 & 467 & 78.2 & 10 & 851 & 829 & 97.4 & 8 & 943 & 922 & 97.8 & 11 & 891 & 730 & 81.9 & 20 \\
\hline Maintirano & 2010-07-19 & -- & -- & -- & -- & -- & -- & -- & -- & -- & -- & -- & -- & 354 & 311 & 87.9 & 25 & 675 & 467 & 69.2 & 50 \\
\hline Mananjara & $2010-02-18$ & -- & -- & -- & -- & -- & -- & -- & -- & -- & -- & -- & -- & 853 & 822 & 96.4 & 27 & 409 & 299 & 73.1 & 35 \\
\hline Mandritsara & $2011-09-26$ & -- & -- & -- & -- & -- & -- & -- & -- & -- & -- & -- & -- & -- & -- & -- & -- & 391 & 391 & 100.0 & 37 \\
\hline Maroantsetra & $2010-09-02$ & -- & -- & -- & -- & -- & -- & -- & -- & -- & -- & -- & -- & 158 & 158 & 100.0 & 18 & 433 & 240 & 55.4 & 28 \\
\hline Miandrivaza & $2010-05-07$ & -- & -- & -- & -- & -- & -- & -- & -- & -- & -- & -- & -- & 875 & 875 & 100.0 & 37 & 582 & 493 & 84.7 & 46 \\
\hline Moramanga & $2007-04-12$ & 1436 & 1436 & 100.0 & NA & 2227 & 2196 & 98.6 & 18 & 3213 & 2964 & 92.3 & 15 & 1454 & 1396 & 96.0 & 23 & 1730 & 1010 & 58.4 & 20 \\
\hline Morombe & 2011-09-12 & -- & -- & -- & -- & -- & -- & -- & -- & -- & -- & -- & -- & -- & -- & -- & -- & 158 & 130 & 82.3 & 21 \\
\hline Morondava & 2007-04-10 & 623 & 623 & 100.0 & NA & 1163 & 1163 & 100.0 & 5 & 1182 & 1182 & 100.0 & 8 & 707 & 707 & 100.0 & 21 & 617 & 426 & 69.0 & 37 \\
\hline Nosy Be & 2009-06-02 & -- & -- & -- & -- & -- & -- & -- & -- & 2402 & 18 & 0.7 & 28 & 2645 & 1100 & 41.6 & 54 & 2542 & 791 & 31.1 & 68 \\
\hline Sainte Marie & 2010-03-04 & -- & -- & -- & -- & -- & -- & -- & -- & -- & -- & -- & -- & 71 & 35 & 49.3 & 46 & 61 & 6 & 9.8 & 41 \\
\hline Sambava & 2009-01-21 & -- & -- & -- & -- & -- & -- & -- & -- & 1125 & 574 & 51.0 & 25 & 1515 & 279 & 18.4 & 40 & 934 & 242 & 25.9 & 50 \\
\hline Taolagnara & $2007-04-24$ & 407 & 407 & 100.0 & NA & 709 & 709 & 100.0 & 15 & 742 & 636 & 85.7 & 17 & 464 & 427 & 92.0 & 23 & 383 & 320 & 83.6 & 35 \\
\hline Toamasina & 2007-04-16 & 1140 & 1140 & 100.0 & NA & 2602 & 2602 & 100.0 & 14 & 3803 & 2727 & 71.7 & 11 & 2428 & 2159 & 88.9 & 24 & 2116 & 1713 & 81.0 & 24 \\
\hline Tsiroanamandidy & $2007-04-30$ & 1056 & 1056 & 100.0 & NA & 1152 & 1152 & 100.0 & 13 & 1199 & 1199 & 100.0 & 36 & 1093 & 1048 & 95.9 & 48 & 1024 & 602 & 58.8 & 45 \\
\hline Tulear & $2007-04-30$ & 352 & 352 & 100.0 & NA & 706 & 706 & 100.0 & 15 & 576 & 499 & 86.6 & 26 & 714 & 711 & 99.6 & 25 & 653 & 494 & 75.7 & 33 \\
\hline Total & & 9,636 & 9,633 & 99.9 & & 16,742 & 16,579 & 99.0 & & 25,884 & 19,969 & 77.1 & & 24,455 & 19,992 & 81.7 & & 25,483 & 16,160 & 63.4 & \\
\hline
\end{tabular}


Early-warning health and process indicators for sentinel surveillance in

OJPHI

Madagascar 2007-2011

Table 3: Number of declared syndromes by sentinel site and year

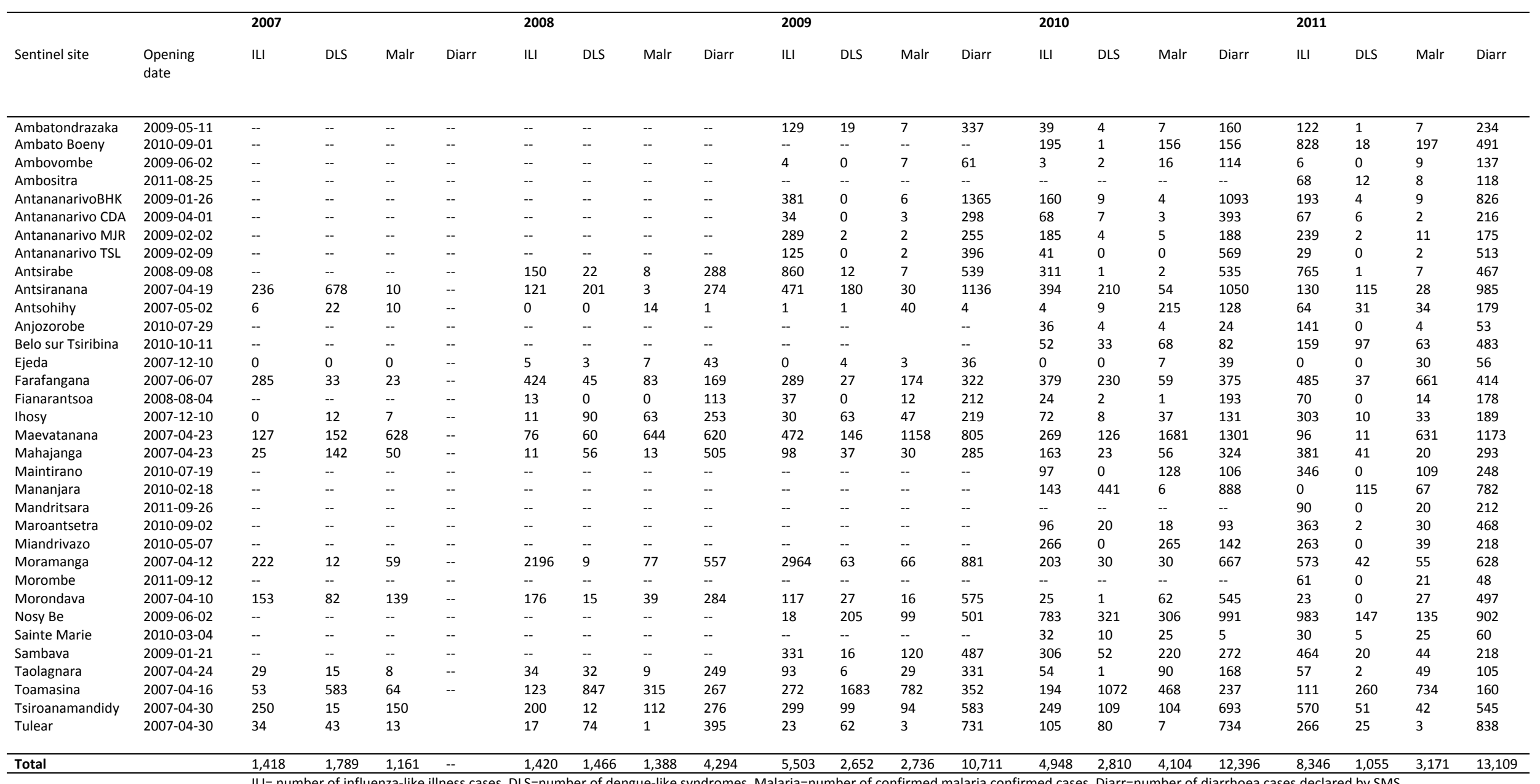

Online Journal of Public Health Informatics * ISSN 1947-2579 * http://ojphi.org * 6(3):e197, 2014 

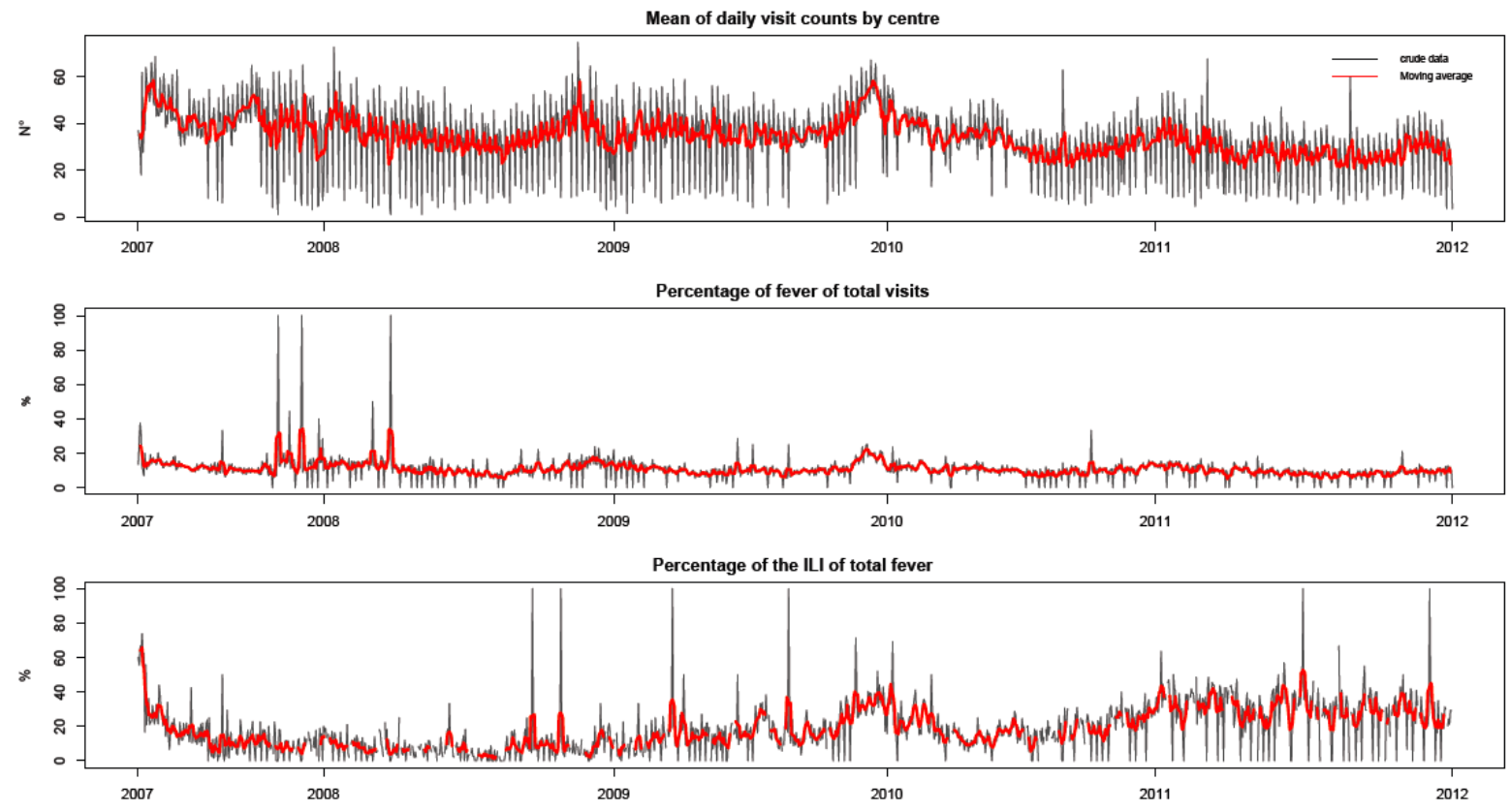

Figure 2: Mean daily visit counts, by centre, in the sentinel surveillance system in Madagascar and daily sentinel surveillance time series plots (\%) of fever, total visits and the ILI cases among total fever cases, with the moving average (over 10 days - red curve) for daily visit counts, April 14, 2007 - December 31, 2011.
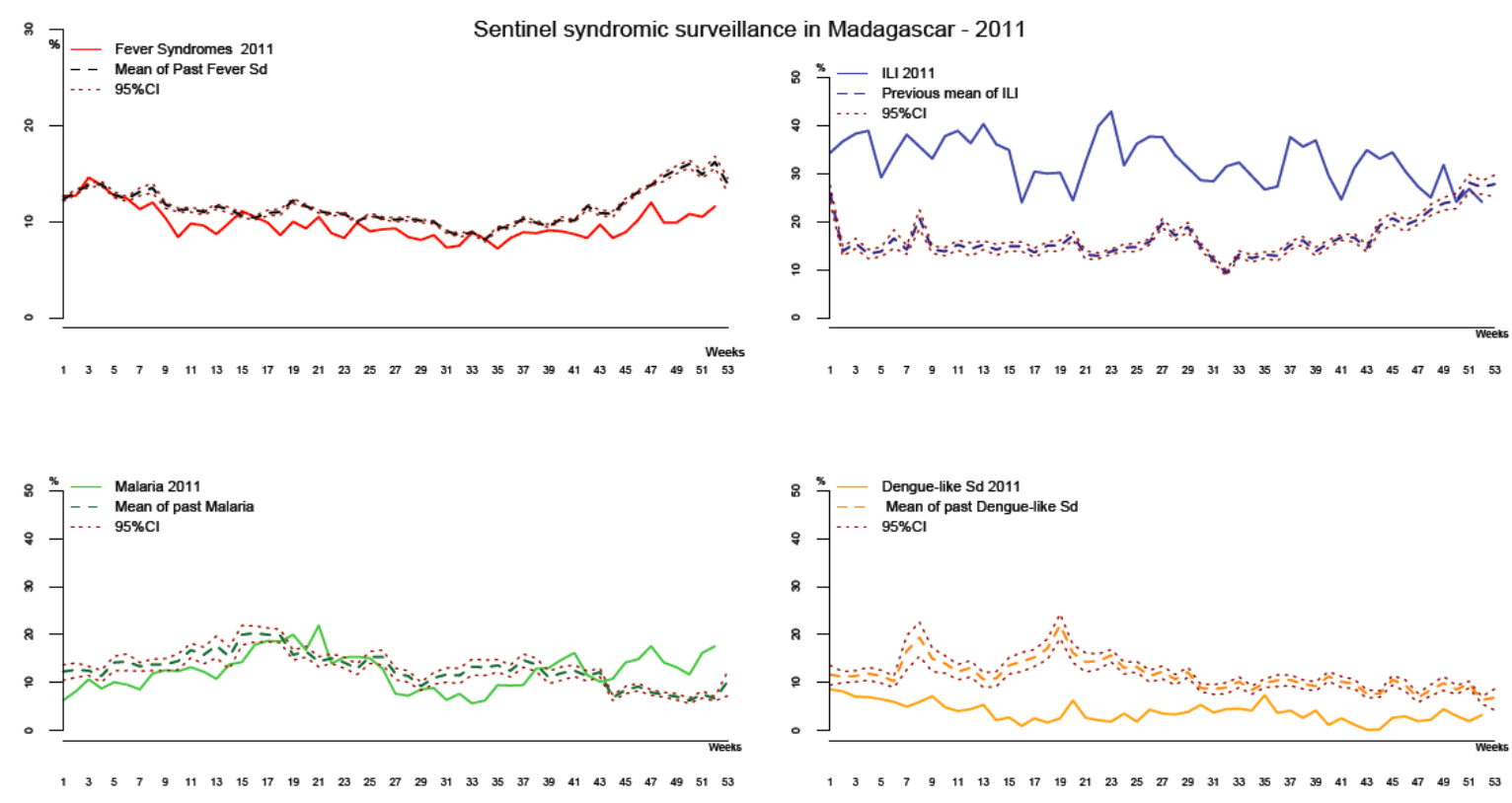

Figure 3: Weekly syndromic data from all sentinel centres in 2011. 


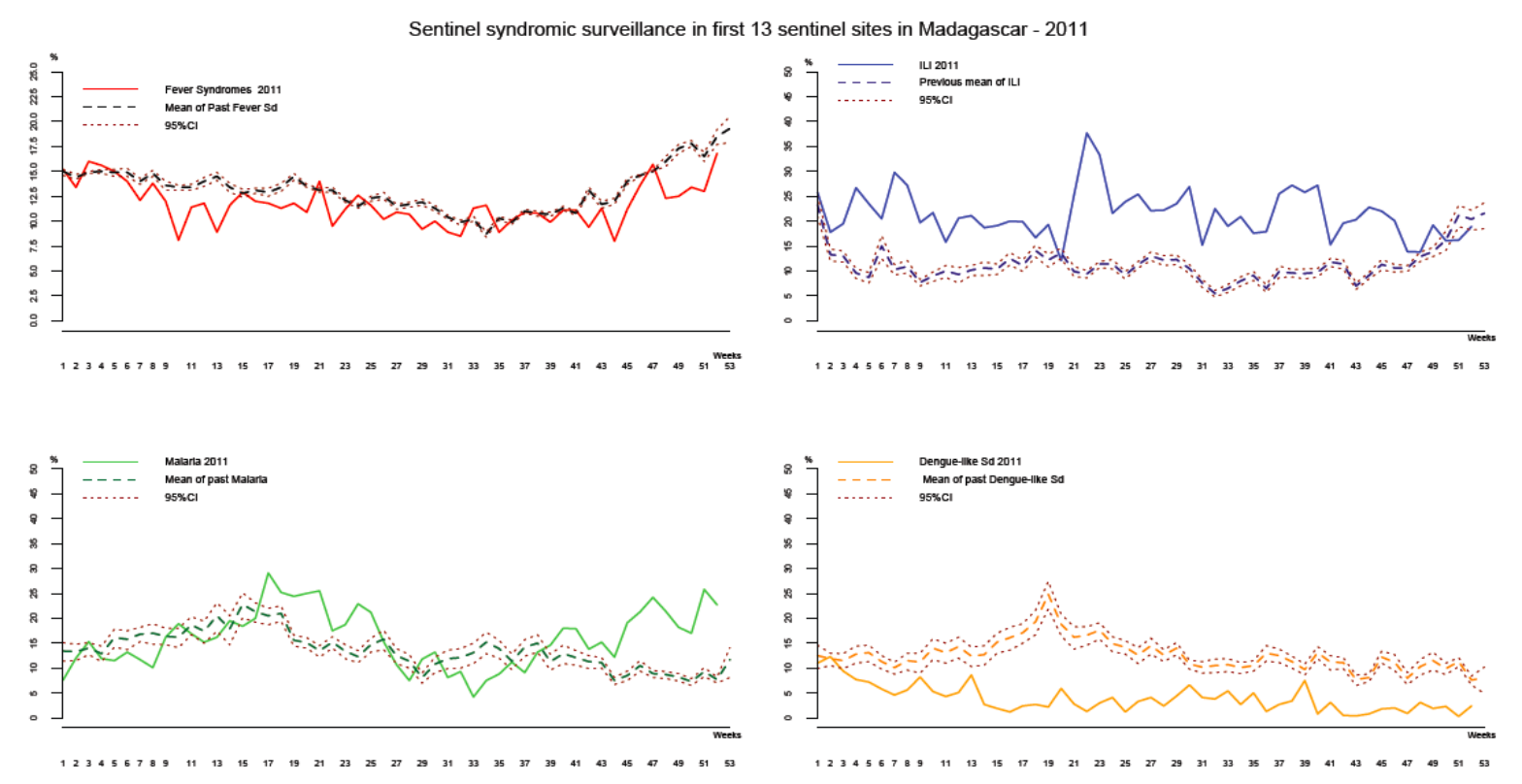

Figure 4: Weekly syndromic data from the first 13 sentinel centres in 2011

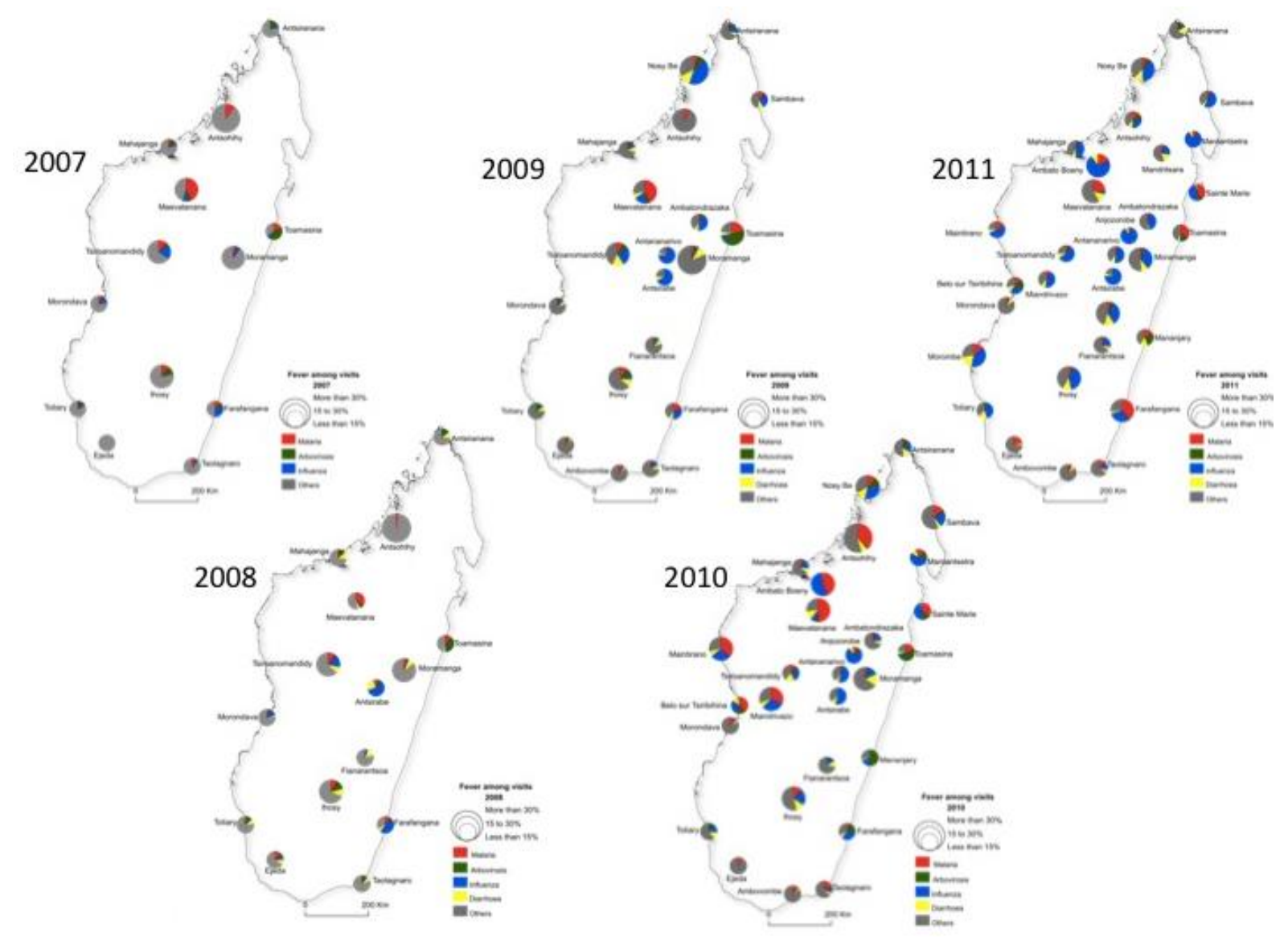

Figure 5: Annual percentage of fever-related syndromes, by centre, based on data collected from sentinel centres by SMS, from 2007 to 2011. 


\section{Alerts}

From 2007 to 2011, 21 alerts resulting from syndromic surveillance were confirmed by biological surveillance and led to a response and epidemiological investigations to assess the risk.

In October 2008, in Morondava, on the west coast of Madagascar, an increase in the percentage of febrile syndromes and the percentage of ILI cases was recorded. Samples were requested and influenza virus $\mathrm{A}(\mathrm{H} 3 \mathrm{~N} 2)$ was detected.

In January 2009, an increase in the percentage of febrile syndromes and in the number of confirmed malaria cases was identified, leading to an investigation of factors potentially associated with an increase in malaria transmission.

In 2010, excess cases of dengue-like syndromes were declared in Mananjary health district, which is located on the southeast coast. The Chikungunya virus was identified and the epidemic confirmed.

None of these events were detected by the routine surveillance system. However, there was no organised response to any of these outbreaks because the MoH lacked the means to deal with these large events.

\section{Process indicators}

Relevant process indicators have been identified for the monitoring of the network. These indicators are presented in Table 2 and concern principally the data transmission and data validation processes.

Overall, $85 \%$ of the data were transmitted within the 24-hour time frame. This indicator was introduced in 2008. The percentage of data for which transmission was delayed increased from $2008(12.3 \%)$ to 2011 (32.6\%), and considerable differences between sentinel sites were observed for this indicator (Table 3).

As previously described [11,12], an individual fever form had to be completed and sent to the IPM for each declared case of febrile syndrome. The fever forms were used to validate the syndrome data transmitted by SMS. Specific forms relating to fever were completed for 82,333 of the patients presenting fever (80.6\%). In 2007, $99.9 \%$ of the febrile syndromes were documented on a fever form, but this percentage had fallen to $63.4 \%$ by 2011 .

The sex ratio (male/female) for those with febrile syndromes was 0.88 . Age was known for 81,981 patients $(99.5 \%)$, and the mean age of the patients was 12.5 years (CI 95\%: [12.412.7]). The age-group distribution is presented in Table 4. ILI, defined on the basis of the symptoms noted on the fever forms (fever and cough, or fever and sore throat), accounted for $49.4 \%(40,709)$ of all cases of febrile illness, but significant differences in these percentages $(p<0.01)$ were found between years: $49.2 \%(4,739 / 9,633)$ in $2007,53.6 \%(8,884 / 16,579)$ in $2008,55.6 \%(11,102 / 19,969)$ in $2009,42.8 \%(8,563 / 19,992)$ in 2010 and $45.9 \%$ $(7,421 / 16,160)$ in 2011. 
Table 4: Annual distribution of febrile illnesses by age group, according to data from individual fever forms

\begin{tabular}{llllllllllllll}
\hline Age group & \multicolumn{1}{c}{ Febrile syndromes $(81,981$ data available from 82,222 individuals forms) } \\
& $\mathbf{2 0 0 7}$ & & $\mathbf{2 0 0 8}$ & $\mathbf{2 0 0 9}$ & $\mathbf{2 0 1 0}$ & $\mathbf{2 0 1 1}$ & \\
\hline & $n$ & $(\%)$ & $n$ & $(\%)$ & $n$ & $(\%)$ & $n$ & $(\%)$ & $n$ & $(\%)$ \\
\hline$<1$ year & 1,601 & $(16.6)$ & 2,887 & $(17.1)$ & 2,916 & $(14.5)$ & 2,923 & $(14.4)$ & 2,375 & $(14.7)$ \\
1-4 years & 3,122 & $(32.3)$ & 5,391 & $(31.9)$ & 5,396 & $(26.9)$ & 6,096 & $(30.0)$ & 4,864 & $(30.1)$ \\
5-14 years & 1,775 & $(18.4)$ & 3,110 & $(18.4)$ & 4,905 & $(24.4)$ & 4,529 & $(22.3)$ & 3,743 & $(23.1)$ \\
$15-24$ years & 1,156 & $(12.0)$ & 2,177 & $(12.9)$ & 3,057 & $(15.2)$ & 2,983 & $(14.7)$ & 2,253 & $(13.9)$ \\
$\geq 25$ years & 1,837 & $(19.0)$ & 3,145 & $(18.6)$ & 3,563 & $(17.7)$ & 3,542 & $(17.4)$ & 2,635 & $(16.3)$ \\
\hline Total & 9,491 & $(11.6)$ & 16,710 & $(20.4)$ & 19,837 & $(24.2)$ & 20,073 & $(24.5)$ & 15870 & $(19.3)$ \\
\hline
\end{tabular}

\section{Discussion}

The sentinel surveillance system in Madagascar has two key functions: it provides an early warning of potential threats to public health and it can be used to manage public health programmes, by providing data for malaria indicators, for example. It can rapidly detect unexpected increases in the incidence of fever or diarrhoea syndromes and the biological surveillance associated with the syndromic surveillance programme can then identify the causes of these syndromes.

This system has been described in terms of the methods used [11] and in relation to aspects of influenza surveillance [12,13], such as the spread of the influenza $\mathrm{A}(\mathrm{H} 1 \mathrm{~N} 1) \mathrm{pdm} 09$ virus $[14,15]$. During the influenza $\mathrm{A}(\mathrm{H} 1 \mathrm{~N} 1) \mathrm{pdm} 09$ pandemic, the circulation of this virus in Madagascar was detected and the spread of the virus was followed from October 2009 to March 2010 [14]. We have already highlighted the weaknesses of the routine disease surveillance system in Madagascar, which is based on passive collection and limited capacities for diagnosis outside the capital city. None of the early-warning signs was identified by routine surveillance. Routine surveillance is useful for monitoring long-term programmes, but inappropriate for the timely detection of aberrant patterns. By contrast, syndrome-based near-real time surveillance can detect unusual events more rapidly [15-18]. This timeliness is a key element of the surveillance system and should be evaluated periodically [19].

The evaluation of surveillance systems should promote the most effective use of public health resources, by ensuring that surveillance systems operate efficiently [20]. The sentinel system in Madagascar was clearly simple and rapid, but we found that some process indicators tended to decline over time, due to high staff turnover. The decrease in the number of fever forms received annually, between 2007 and 2011, is one of the weaknesses of this system. The increase in the number of sentinel sites increased the workload of central staff managing the different activities. A lack of co-ordination hindered the training of new healthcare workers entering the network, and changes in practices were discovered only during supervision in the field. Challenges resulting from high staff turnover have also been identified in other 
countries [6,8]. The indicators used for the continuous assessment of the sentinel network in Madagascar are useful for a rapid, basic internal evaluation, but an external evaluation approach is also required, using CDC guidelines [21], for example, and including economic indicators as an integral part of the surveillance evaluation process [4].

The choice of methods used in the sentinel surveillance system in Madagascar was based on the capabilities of the volunteer healthcare providers and the financial resources available. The Madagascan network has grown over the years and its expansion is probably now limited by the human resources required to manage the network and data analysis. We have found that progressive step-by-step implementation is best, with assessment of the various processes, evaluations of network management capacity and the training of healthcare workers, to make the processes more acceptable.

Despite the results obtained to date, the sustainability of this system remains unclear, although data transmission costs amount to only about 2 US dollars per sentinel site per month. The Madagascan network has been supported by funding from various sources over the years, focusing on different health topics. Self-sustainability is another challenge, as already described [8], and has already been identified as a weakness of this network. We therefore need to focus on the first steps of surveillance system implementation and all system changes. Initial funds targeted arbovirosis, because of the spread of Chikungunya epidemics in Indian Ocean countries in 2006, and influenza, due to the threat posed by avian flu. However, the steering committee subsequently decided to include other diseases associated with febrile syndromes. This policy has been tremendously successful, making it possible for the network to provide epidemiological information not only about arboviruses, but also about malaria and influenza, throughout the country. In 2008, the first human case of Rift Valley fever was detected, by this network, at Taolognaro (in the south of the country), a site used for both syndromic and biological surveillance. For malaria, the network has monitored the shift from control to elimination following the strengthening of malaria prevention and control measures. The usefulness of sentinel networks for influenza detection is well documented and was assessed in the last pandemic period in 2009 [15]. Funding for work on these diseases has improved geographical coverage and made it possible to extend the network over the last five years. This network has become an additional tool for public health decision-making. The syndromic surveillance has been shown to be an effective approach to surveillance and, thanks to the availability of large mobile phone networks throughout Madagascar, the cost of real-time data transmission is low. This surveillance method may also facilitate compliance with the revised International Health Regulations for low-income countries and the aim of the Global Outbreak Alert and Response Network (GOARN) [22].

\section{Limitations}

However, the rapidity with which the system can identify unexpected events, which is seen as an advantage [23], must be weighed against delays in the response. For instance, the time required to conduct investigations and retrieve diagnostic and epidemiological information might negate the advantage of rapid data acquisition, particularly in developing countries, in which it can be hard to find the resources necessary for investigations.

The lack of historical data made it difficult to interpret the syndromic trends at each sentinel centre. One of the challenges in our system is determining epidemiological baselines for each centre, to facilitate the development of better statistical methods and more sensitive alert thresholds, as suggested by several authors [24-28]. Indeed, five years after the establishment of this network, large amounts of data are already available and data analysis methods have identified trends for ILI, malaria and dengue-like syndromes in areas of Madagascar with 
different climates. We now need to develop spatiotemporal models to increase the sensitivity of the alert detection process. However, limited geographical coverage and limited resources may prevent the detection of some epidemic events by this network.

\section{Conclusion}

It is clear that the greatest advantage of this system is the ease with which it can be implemented, thanks to the availability of mobile phones and mobile phone networks. Furthermore the quality of the homogeneous data collected will make it possible to improve the system relative to its principal objective: identifying epidemic events early. We recommend this solution for other African countries, because it performs very well and provides rapid benefits in terms of public health decision-making.

\section{Financial support}

This work was made feasible by the setting up of a sentinel network supported by WHO Geneva (APW/Ref. OD/AP-08-02451), the French Ministry of Health, the Madagascan Ministry of Health through "projet CRESAN" (crédit IDA - 3302-1-MAG (CRESAN-2)), the US Centers for Disease Control and Prevention (Cooperative Agreement Number: U51/IP000327-01), the US Department of Health and Human Service (Grant Number 6 IDSEP060001-01-01) via the International Network of Pasteur Institutes and the President's Malaria Initiative program (USAIDS). We would like to thank Kathleen Victoir and Marc Jouan from the International Network of Pasteur Institutes.

\section{Competing interests}

The authors have no competing interests to declare.

\section{Acknowledgements}

We thank all the staff from the Madagascan National Influenza Centre for influenza testing (Julia Guillebaud, Arnaud Orelle, Girard Razafitrimo and Vololoniaina Raharinosy), and the National Laboratory for Arbovirus (Jean Théophile Rafisandrantantsoa, Jean-Pierre Ravalohery and Josette Razainirina) for all laboratory tests.

We would like to express our gratitude to Dr Yolande Nirina Raoelina, who was one of the key people involved in setting up the sentinel network, and all the staff from the $\mathrm{MoH}$. We are deeply indebted to all the doctors and nurses involved in sentinel surveillance on a daily basis in Madagascar.

\section{References}

1. Heymann (editor). Control of Communicable Diseases Manual. 18th éd. USA: APHA; 2004.

2. Last JM. A dictionary of epidemiology. 4th éd. Oxford University Press; 2001.

3. Eylenbosch WJ, Noah NG. Surveillance in Health and Disease. Oxford University Press; 1988.

4. Drewe JA, Hoinville LJ, Cook AJC, Floyd T, Stärk KDC. 2012. Evaluation of animal and public health surveillance systems: a systematic review. Epidemiol Infect. 140(4), 575-90. PubMed http://dx.doi.org/10.1017/S0950268811002160

5. Huaman MA, Araujo-Castillo RV, Soto G, Neyra JM, Quispe JA, et al. 2009. Impact of two interventions on timeliness and data quality of an electronic disease surveillance 
system in a resource limited setting (Peru): a prospective evaluation. BMC Med Inform Decis Mak. 9, 16. PubMed http://dx.doi.org/10.1186/1472-6947-9-16

6. Chretien J-P, Lewis SH. Electronic public health surveillance in developing settings: meeting summary. BMC Proc. 2008;2 Suppl 3:S1.

7. Ijaz K, Kasowski E, Arthur RR, Angulo FJ, Dowell SF. 2012. International Health Regulations--What Gets Measured Gets Done. Emerg Infect Dis. 18(7), 1054-57. PubMed http://dx.doi.org/10.3201/eid1807.120487

8. Soto G, Araujo-Castillo RV, Neyra J, Fernandez M, Leturia C, et al. Challenges in the implementation of an electronic surveillance system in a resource-limited setting: Alerta, in Peru. BMC Proc. 2008;2 Suppl 3:S4.

9. Chretien J-P, Burkom HS, Sedyaningsih ER, Larasati RP, Lescano AG, et al. 2008. Syndromic surveillance: adapting innovations to developing settings. PLoS Med. 5(3), e72. PubMed http://dx.doi.org/10.1371/journal.pmed.0050072

10. Raviglione MC, Gupta R, Dye CM, Espinal MA. 2001. The burden of drug-resistant tuberculosis and mechanisms for its control. Ann N Y Acad Sci. 953, 88-97. PubMed http://dx.doi.org/10.1111/j.1749-6632.2001.tb11364.x

11. Randrianasolo L, Raoelina Y, Ratsitorahina M, Ravolomanana L, Andriamandimby S, et al. 2010. Sentinel surveillance system for early outbreak detection in Madagascar. BMC Public Health. 10, 31. PubMed http://dx.doi.org/10.1186/1471-2458-10-31

12. Rajatonirina S, Heraud J-M, Randrianasolo L, Orelle A, Razanajatovo NH, et al. 2012. Short message service sentinel surveillance of influenza-like illness in Madagascar, 20082012. Bull World Health Organ. 90(5), 385-89. $\quad \underline{\text { PubMed }}$ http://dx.doi.org/10.2471/BLT.11.097816

13. Razanajatovo NH, Richard V, Hoffmann J, Reynes J-M, Razafitrimo GM, et al. 2011. Viral etiology of influenza-like illnesses in antananarivo, madagascar, july 2008 to june 2009. PLoS ONE. 6(3), e17579. PubMed http://dx.doi.org/10.1371/journal.pone.0017579

14. Rajatonirina S, Heraud J-M, Orelle A, Randrianasolo L, Razanajatovo N, et al. 2012. The Spread of Influenza A(H1N1)pdm09 Virus in Madagascar Described by a Sentinel Surveillance Network. PLoS ONE. 7(5), e37067. http://dx.doi.org/10.1371/journal.pone.0037067

15. Orelle A, Razanajatovo NH, Rajatonirina S, Hoffmann J, Randrianasolo L, et al. 2012. Epidemiological and virological characterization of 2009 pandemic influenza A virus subtype H1N1 in Madagascar. J Infect Dis. 206(Suppl 1), S140-47. PubMed http://dx.doi.org/10.1093/infdis/jis533

16. Buehler JW, Berkelman RL, Hartley DM, Peters CJ. 2003. Syndromic surveillance and bioterrorism-related epidemics. Emerg Infect Dis. 9(10), 1197-204. PubMed http://dx.doi.org/10.3201/eid0910.030231

17. Lewis MD, Pavlin JA, Mansfield JL, O’Brien S, Boomsma LG, et al. 2002. Disease outbreak detection system using syndromic data in the greater Washington DC area. Am J Prev Med. 23(3), 180-86. PubMed http://dx.doi.org/10.1016/S0749-3797(02)00490-7

18. Miller B, Kassenborg H, Dunsmuir W, Griffith J, Hadidi M, et al. 2004. Syndromic surveillance for influenzalike illness in ambulatory care network. Emerg Infect Dis. 10(10), 1806-11. PubMed http://dx.doi.org/10.3201/eid1010.030789 
19. Jajosky RA, Groseclose SL. 2004. Evaluation of reporting timeliness of public health surveillance systems for infectious diseases. BMC Public Health. 4(1), 29. PubMed http://dx.doi.org/10.1186/1471-2458-4-29

20. CDC. 1988. Guidelines for evaluating surveillance systems. MMWR Morb Mortal Wkly Rep. 37(S-5), 1-18. PubMed

21. German RR, Lee LM, Horan JM, Milstein RL, Pertowski CA, Waller MN. Updated guidelines for evaluating public health surveillance systems: recommendations from the Guidelines Working Group. MMWR Recomm Rep. 27 juill 2001;50(RR-13):1-35; quiz CE1-7.

22. Heymann DL, Rodier GR. 2001. Hot spots in a wired world: WHO surveillance of emerging and re-emerging infectious diseases. Lancet Infect Dis. 1(5), 345-53. PubMed http://dx.doi.org/10.1016/S1473-3099(01)00148-7

23. Wu T-SJ, Shih F-YF, Yen M-Y, Wu J-SJ, Lu S-W, et al. 2008. Establishing a nationwide emergency department-based syndromic surveillance system for better public health responses in Taiwan. BMC Public Health. 8, 18. PubMed http://dx.doi.org/10.1186/1471$\underline{2458-8-18}$

24. Flahault A, Blanchon T, Dorléans Y, Toubiana L, Vibert JF, et al. 2006. Virtual surveillance of communicable diseases: a 20-year experience in France. Stat Methods Med Res. 15(5), 413-21. PubMed

25. Viboud C, Boëlle P-Y, Carrat F, Valleron A-J, Flahault A. 2003. Prediction of the spread of influenza epidemics by the method of analogues. Am J Epidemiol. 158(10), 996-1006. PubMed http://dx.doi.org/10.1093/aje/kwg239

26. Costagliola D, Flahault A, Galinec D, Garnerin P, Menares J, et al. 1991. A routine tool for detection and assessment of epidemics of influenza-like syndromes in France. Am J Public Health. 81(1), 97-99. PubMed http://dx.doi.org/10.2105/AJPH.81.1.97

27. Pelat C, Boëlle P-Y, Cowling BJ, Carrat F, Flahault A, et al. 2007. Online detection and quantification of epidemics. BMC Med Inform Decis Mak. 7, 29. PubMed http://dx.doi.org/10.1186/1472-6947-7-29

28. Saltyte Benth J, Hofoss D. 2008. Modelling and prediction of weekly incidence of influenza A specimens in England and Wales. Epidemiol Infect. 136(12), 1658-66. $\underline{\text { PubMed http://dx.doi.org/10.1017/S0950268808000307 }}$ 